\title{
Be-7 and Th-234 as tracers of sediment mixing on seasonal time scale at the water-sediment interface of the Thau Lagoon
}

\author{
P. Lecroart ${ }^{1}$, S. Schmidt ${ }^{1,2}$, J.-M. J ouanneau ${ }^{1}$ and O. Weber ${ }^{1}$ \\ ${ }^{1}$ UMR 5805 EPOC, Département de Géologie et d'Océanographie, 33405 Talence, France \\ ${ }^{2}$ UMR 1572 LSCE, 91198 Gif-sur-Yvette Cedex, France
}

\begin{abstract}
We report detailed depth profiles of the particle-reactive radionuclides ${ }^{234} \mathrm{Th}(24.1$ days $)$ and ${ }^{7} \mathrm{Be}$ (53.3 days) in sediment cores collected at different seasons in the Thau Lagoon, located in the south of France. Two sites with contrasting characteristics were selected: C4 in the middle of the lagoon and C5 nearby oyster farming. Both sites were visited six times between December 2001 and May $2003 .{ }^{234} \mathrm{Th}$ in excess ${ }^{234} \mathrm{Th}_{\mathrm{xs}}$; i.e. supplied to sediment by settling particles) and ${ }^{7} \mathrm{Be}$ both show seasonal variations in activities and in penetration within sediment. With their very short half-lives and moderate sedimentation rates at both sites (around $0.1-0.3 \mathrm{~cm}$ per year), ${ }^{234} \mathrm{Th}_{\mathrm{xs}}$ and ${ }^{7} \mathrm{Be}$ should be present only at the water-sediment interface. However all the profiles show penetration of both short-lived radionuclides to variable depths, from 1 up to $8 \mathrm{~cm}$, that indicates efficient biological mixing of upper sediments. Such a mixing is usually described as a biodiffusive transport defined by bioturbation coefficient $\left(\mathrm{D}_{\mathrm{b}}\right)$. The simplest way to calculate $\mathrm{D}_{\mathrm{b}}$ from radionuclide profiles is to assume steady-state within the mixed layer. For site $\mathrm{C} 4$, steady-state bioturbation rates $\left(\mathrm{D}_{\mathrm{b}}\right.$-SS) range between 1 and $12 \mathrm{~cm}^{2} \mathrm{yr}^{-1}$, with a weak seasonal signal. The mixing of surface sediments at site $\mathrm{C} 5$ presents a greater range $\left(1-31 \mathrm{~cm}^{2} \mathrm{yr}^{-1}\right)$ with the highest values observed in summer. Radionuclide fluxes at the water-sediment interface show too seasonal variations, particularly marked at site $\mathrm{C} 5$ in relation with its position. Such a time-series of short radionuclides at the water-sediment is most unusual. It provides the opportunity to develop a non-steady state modelling in order to test the significance of bioturbation rates based on steady state assumption. These tests allow to figure out how variations (seasonal, episodic) of radionuclide fluxes could induce errors on $\mathrm{D}_{\mathrm{b}}-\mathrm{SS}$ determinations.
\end{abstract}

\section{INTRODUCTION}

The Thau Lagoon is located on the French Mediterranean coast (Figure 1). This shallow basin is almost closed with only narrow openings to the Mediterranean Sea. In addition to its ecological importance as a recruitment zone for some sea fish species, this ecosystem is of notable interest related to economic activities: tourism, industry and shellfish production [1-2]. Indeed the Thau lagoon is the fourth French site of shellfish cultivation, i.e. roughly $10 \%$ of the national production, with about 15000 tons of oysters and nearly 4000 tons of mussels per year [3]. However, the Thau lagoon suffers regularly from two natural problems: proliferation of toxic algae, Alexandrium, which prevents temporarily shellfish trade, and anoxic crises, known as malaïgues, which could induce shellfish mortality [4]. Such a context explains the number of studies carried out within the last decades to investigate the behaviour of this lagunar ecosystem.

The present work is a part of the PNEC Microbent programme, which focuses on the exchange between the water column and sediments. In order to assess such processes, a better knowledge of the sedimentation processes (sedimentation,) is required. Particle-reactive radionuclides have been often used, during the last two decades, as chronometers for estimating accumulation and particle reworking in marine and lake sediments [5]. For the Thau, sedimentation rates derived from ${ }^{210} \mathrm{~Pb}_{\mathrm{xs}}$ range from $0.15 \mathrm{~cm} \mathrm{y}^{-1}$ at the edge of the basin (site C5), to $0.25 \mathrm{~cm} \mathrm{y}^{-1}$ at the central site [6]. In this paper, we present the investigation of the short-term sediment dynamic at the water-sediment interface. Results are based on detailed depth profiles of two short-lived radionuclides, ${ }^{234} \mathrm{Th}$ (24.1 days) and ${ }^{7} \mathrm{Be}$ (53 days), in sediment 
cores collected at different seasons. These data are interpreted in order to provide bioturbation rates $\left(D_{b}\right)$ for the Thau lagoon. This unique time-series provide the opportunity to address the significance of seasonal variation in $\mathrm{D}_{\mathrm{b}}$, calculated using classical steady-state treatment of radionuclide data.

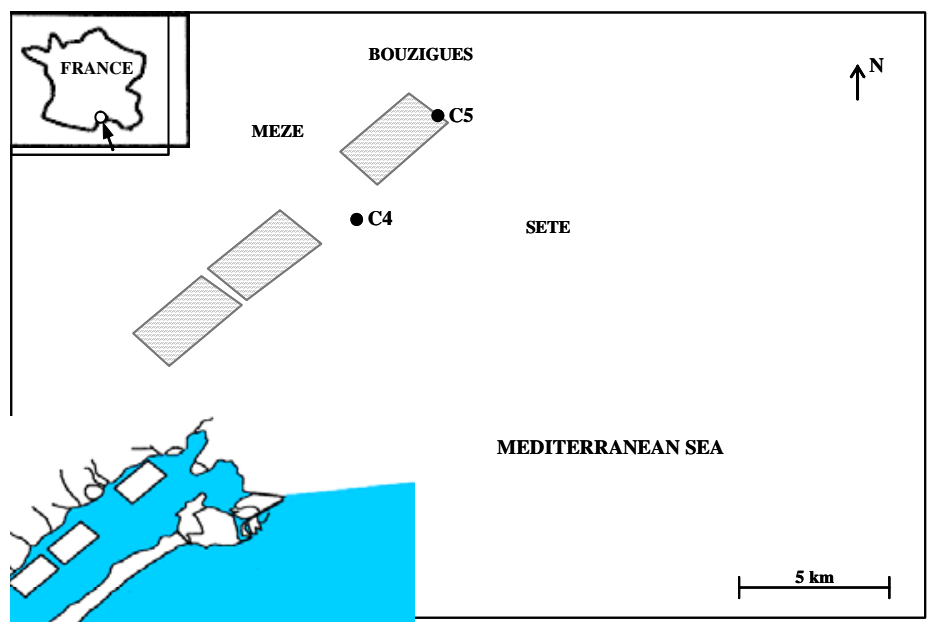

Figure 1. Location of the sampling area (dashed area: oyster farming).
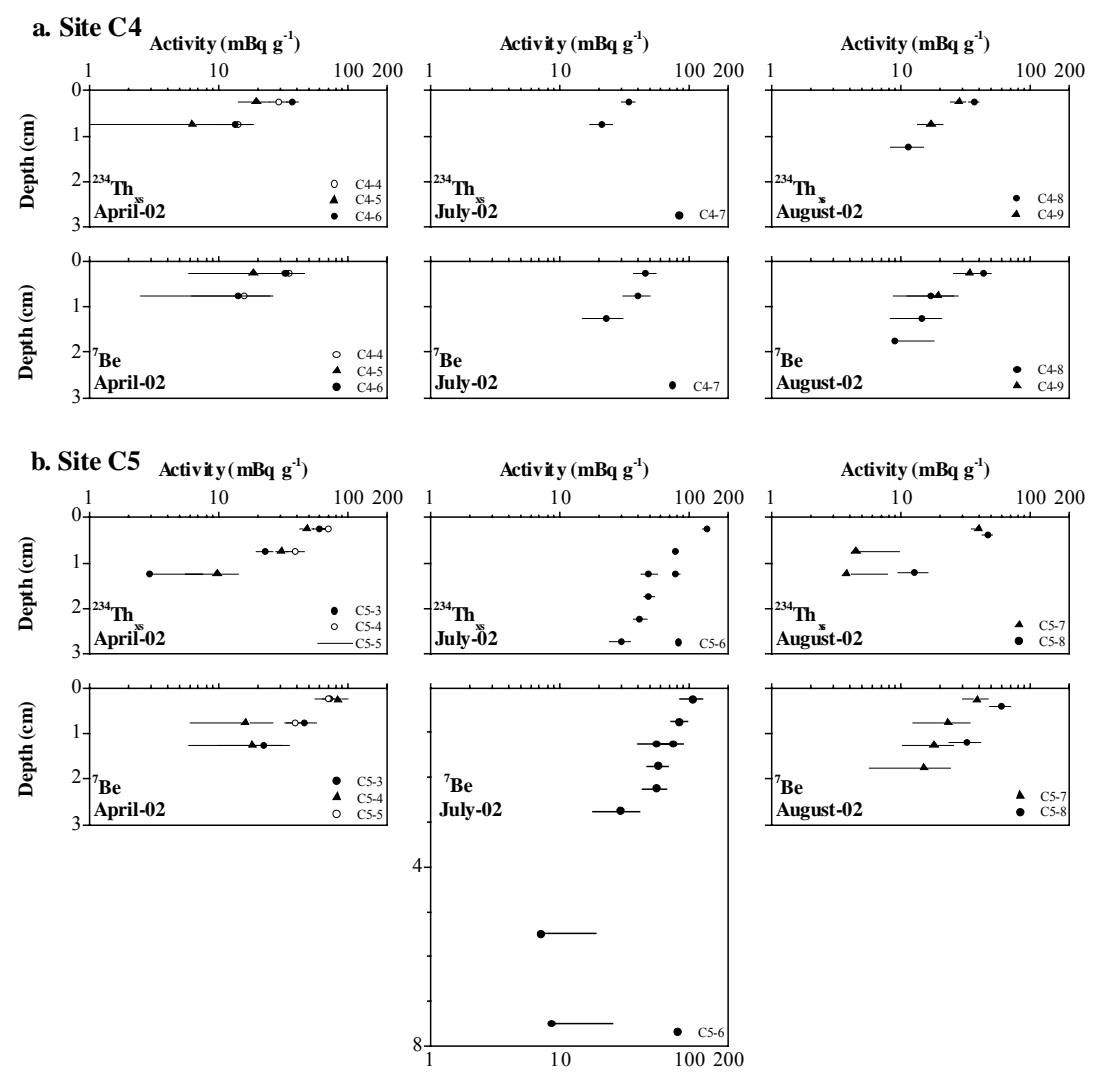

Figure 2. Excess ${ }^{234} \mathrm{Th}$ and ${ }^{7} \mathrm{Be}$ versus depth in sediments of the Thau lagoon for year 2002 . The upper panel corresponds to site $\mathrm{C} 4$ (a), the lower to site $\mathrm{C} 5$ (b). The complete data set is presented in [6]. 


\section{METHOD}

Repeated field campaigns allowed to sample the water-sediment interface of the Thau Lagoon at sites C4 (8 m depth) and C5 (9 m water depth): in December 2001, April, July and August 2002, January and May 2003. Scuba divers recovered sediment cores, less to $20 \mathrm{~cm}$ in length, by using hand-driven tubes. Immediately after core retrieval, cores were carefully sliced each $1 / 2 \mathrm{~cm}$ by upward extrusion. Back to the lab, sediment samples were sieved at $63 \mu \mathrm{m}$ and dried at $60^{\circ} \mathrm{C}$. Then the uppermost sediment layers were measured for ${ }^{234} \mathrm{Th}$ and ${ }^{7} \mathrm{Be}$ determinations using a low background-high efficiency well type $\gamma$-detector [7]. These measurements had to be completed within one month after sampling, due to the rapid decay of ${ }^{234} \mathrm{Th}$. In fact, measurements of ${ }^{234} \mathrm{Th}$ are not available for few cores. Sediment layers were investigated downcore until the disappearance of ${ }^{7} \mathrm{Be}$ and a rather constant ${ }^{234} \mathrm{Th}$ activity was reached, which was considered as the supported activity. ${ }^{238} \mathrm{U}$ activities were determined by $\alpha$ counting after sediment digestion by a mixture of $\mathrm{HF}-\mathrm{HNO}_{3}-\mathrm{HClO}_{4}$ in presence of ${ }^{232} \mathrm{U}$.

Excess ${ }^{234} \mathrm{Th}$ data were calculated by subtracting the activity supported by its parent isotope, ${ }^{238} \mathrm{U}$, from the total activity in the sediment. Both ${ }^{234} \mathrm{Th}_{\mathrm{xs}}$ and ${ }^{7} \mathrm{Be}$ activities were corrected for radioactive decay that occurred between sample collection and counting.

\section{RESULTS}

Due to their short half-life and the moderate sedimentation rate, both considered radionuclides disappear usually within the 3 first $\mathrm{cm}$ (Figure 2). Most of profiles are limited to few points, but, when collected, replicate cores show a rather good reproducibility. For ${ }^{234} \mathrm{Th}_{\mathrm{xs}}$, activities are moderate when compared to oceanic values $[8,9] .{ }^{7} \mathrm{Be}$ values are in the range of published values [10]. Both ${ }^{234} \mathrm{Th}$ and ${ }^{7} \mathrm{Be}$ show seasonal variations in activities and in penetration within the sediment.

At site $\mathrm{C} 4$, uppermost activities of ${ }^{234} \mathrm{Th}_{\mathrm{xs}}$ and ${ }^{7} \mathrm{Be}$ are comprised between 20 and $72 \mathrm{mBq} \mathrm{g}$. Both radionuclides are never measured deeper than $2 \mathrm{~cm}$. Site $\mathrm{C} 5$ displays a different pattern. Firstly, surface activities present a wider range from 30 to $166 \mathrm{mBq} \mathrm{g}^{-1}$ (Figure 2). This higher variability in activities is associated, to a lesser extent, with an increase in penetration depth, up to $8 \mathrm{~cm}$ for ${ }^{7} \mathrm{Be}$ in July 2002 .

\section{DISCUSSION}

\subsection{Bioturbation rates at the water-sediment interface of the Thau lagoon}

Taking into account short their half-lives (few weeks) and sedimentation rates in the Thau lagoon (around $0.2 \mathrm{~cm} \mathrm{yr}^{-1}$ ), ${ }^{234} \mathrm{Th}_{\mathrm{xs}}$ and ${ }^{7} \mathrm{Be}$ should be present only in the uppermost layer of cores. However all the profiles obtained in this work show penetration of both short-lived radionuclides to variable depths (Figure 2). Such feature reveals the occurrence of an efficient mixing of upper sediment layers, usually referred as bioturbation. Biological mixing is usually assumed as a diffusive transport occurring at a constant rate within a mixed layer of thickness L. Therefore, radioisotope profiles are modeled from the one dimensional advection-diffusion model [11, 12]:

$$
\frac{\partial A}{\partial t}=\mathrm{D}_{\mathrm{b}} \frac{\partial^{2} A}{\partial \mathrm{z}^{2}}-\mathrm{w} \frac{\partial A}{\partial \mathrm{z}}-\lambda A
$$

with $A$, the radionuclide activity $\left(\mathrm{mBq} \mathrm{g}^{-1}\right)$ of ${ }^{7} \mathrm{Be}$ or ${ }^{234} \mathrm{Th}_{\mathrm{xs}}, \mathrm{z}$, the depth in the sediment column $(\mathrm{cm})$, $w$ the sedimentation rate $\left(\mathrm{cm} \mathrm{yr}^{-1}\right), \mathrm{D}_{\mathrm{b}}$, the bioturbation coefficient $\left(\mathrm{cm}^{2} \mathrm{yr}^{-1}\right)$, and $\lambda$, the decay constant of the considered radionuclide $\left(\mathrm{yr}^{-1}\right)$. The model assumes constant porosity, density, sedimentation rate, and bioturbation in the mixing layer.

The simplest way to derive $\mathrm{D}_{\mathrm{b}}$ from radionuclide profiles using equation $(1)$ is to assume steady state $\left(\mathrm{D}_{\mathrm{b}-\mathrm{SS}}\right)$ :

$$
\mathrm{D}_{\mathrm{b}-\mathrm{Ss}} \frac{\partial^{2} A}{\partial \mathrm{z}^{2}}-\mathrm{w} \frac{\partial A}{\partial \mathrm{z}}-\lambda A=0
$$


This method was applied to profiles of ${ }^{234} \mathrm{Th}_{\mathrm{xs}}$ and ${ }^{7} \mathrm{Be}$ of the Thau Lagoon (Figure 3). When duplicates were recovered for a same date, there is a rather good reproduction of profiles and therefore of bioturbation rates. Such a result highlights the robustness of these estimates, even based on few points. Moreover, whatever the considered radionuclides, ${ }^{234} \mathrm{Th}$ or ${ }^{7} \mathrm{Be}$, bioturbation rates, $\mathrm{D}_{\mathrm{b}-\mathrm{ss}}$ are closely comparable. This is not surprising since both radionuclides, carried to sediment by fine particles, have half-live of comparable time scale. Mixing rates obtained in the Thau lagoon are in the lower range of reported values for coastal environment [13].

For site $\mathrm{C} 4$, steady-state bioturbation rates range between 1 and $11 \mathrm{~cm}^{2} \mathrm{yr}^{-1}$, with a weak seasonal signal (Figure 3a). The mixing of surface sediments at site $\mathrm{C} 5$ presents a greater range $\left(1-32 \mathrm{~cm}^{2} \mathrm{yr}^{-1}\right)$ with the highest values observed in summer. Higher bioturbation rates at site $\mathrm{C} 5$ may be in relation with the proximity of oyster cultivation.

Site C4

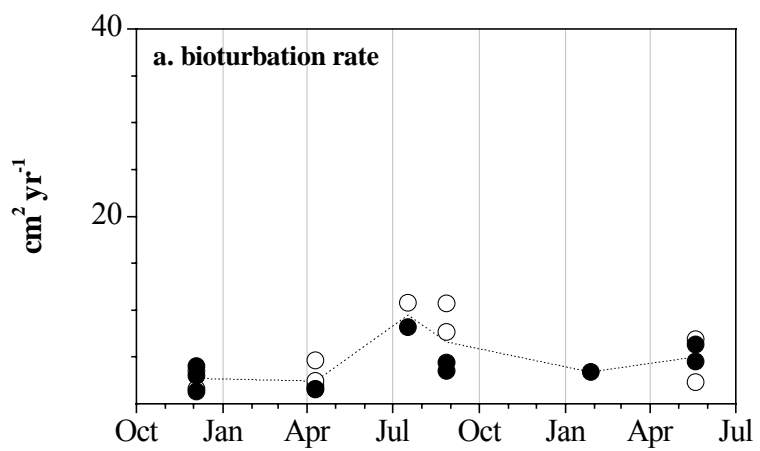

Site C5
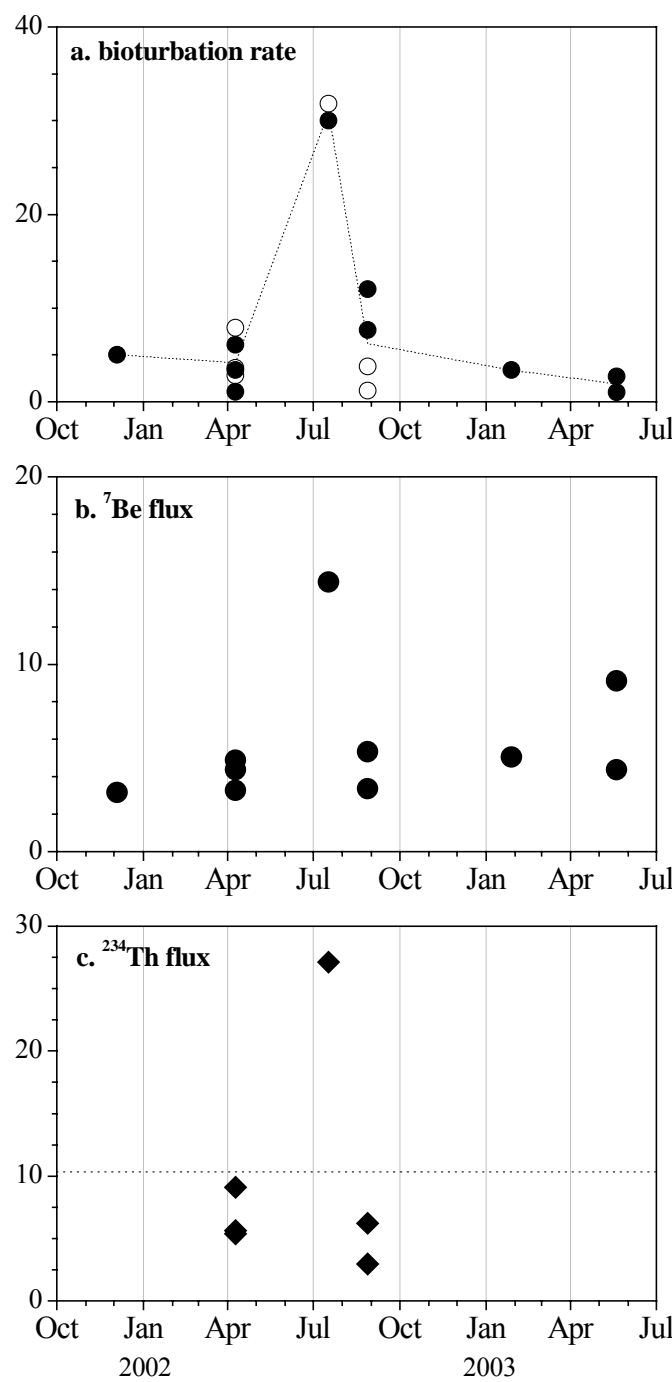

Figure 3. Seasonal trend in (a) bioturbation rates, derived from ${ }^{234} \mathrm{Th}_{\mathrm{xs}}$ (open circles) and $7 \mathrm{Be}$ (dark circles), (b) ${ }^{7} \mathrm{Be}$ and (c) ${ }^{234} \mathrm{Th}_{\mathrm{xs}}$ fluxes at sites C4 (left) and C5 (right) of the Thau Lagoon. Dash lines in uppermost figures (a) correspond to mean bioturbation values for each sampled period. In the lower panel (c), short dot lines represent the mean production rate of ${ }^{234} \mathrm{Th}$ from ${ }^{238} \mathrm{U}$ decay in the water column. 


\subsection{Radionuclide fluxes}

At steady-state, equation (2) can be analytically solved using the two classical boundary conditions. Firstly the flux of radionuclides $(\mathrm{F})$ is imposed at the sediment-water interface and incorporated into the sediment by bioturbation and advection. Secondly, radioisotope activities converge toward zero when the depth goes to infinite. The analytical solution of equation (2) is then:

$$
A(z)=\frac{F}{1-\varphi}\left(\mathrm{w}-\mathrm{D}_{\mathrm{b}} \theta\right) e^{\theta z}
$$

where $\theta$ is defined by:

$$
\theta=\left(\mathrm{w}-\sqrt{\mathrm{w}^{2}+4 \lambda \mathrm{D}_{\mathrm{b}}}\right) / 2 \mathrm{D}_{\mathrm{b}}
$$

Equation (3) allows us to calculate radionuclide flux at the sediment-water interface using a least-square fit and $\mathrm{D}_{\mathrm{b}-\mathrm{ss}}$ values computed in the previous section. The quality of the fit is quantitatively estimated by the root-mean-square parameter $(R M S)$ defined as:

$$
R M S=\sqrt{\frac{\sum_{i}\left(A_{o b s}(i)-A_{f i t}(i)\right)^{2}}{\mathrm{n}}}
$$

where $i$ refers to the depth $z_{i}$ of radioisotope analyses, $A_{o b s}(i)$ is the observed activity at the depth $z_{i}$, $A_{\text {fit }}(i)$ is the least-squares fitted activity at the same depth, and $n$ is the number of depth segments. The $R M S$ expresses the fraction of radioisotope profiles unexplained by biodiffusive mixing. It can be related for instance to non-local bioturbation or to effects of non-relaxed fluxes variations at the sediment-water interface.

Fluxes of ${ }^{7} \mathrm{Be}$ at the sediment-water interface obtained in the Thau lagoon range between 1.5 and 4.2 $\mathrm{Bq} \mathrm{m}^{-2}$ day $^{-1}$ for site $\mathrm{C} 4$ and between 3.2 and $14.4 \mathrm{~Bq} \mathrm{~m}^{-2}$ day $^{-1}$ for site $\mathrm{C} 5$ (Figure $3 \mathrm{~b}$ ). These results are consistent with previously published values for coastal environments at equivalent latitude [14]. Range of ${ }^{234} \mathrm{Th}$ fluxes shows the same trend with highest values reported for site $\mathrm{C} 5$ (Figure $3 \mathrm{c}$ ): from 1.7 to $8.4 \mathrm{~Bq} \mathrm{~m}^{-2} \mathrm{~d}^{-1}$ for site $\mathrm{C} 4$ and from about 3 to $27.1 \mathrm{~Bq} \mathrm{~m}^{-2} \mathrm{~d}^{-1}$ for site $\mathrm{C} 5$.

Whatever the considered radionuclide, site C5 presents always a higher variability, in bioturbation rates and fluxes, when compared to site $\mathrm{C} 4$. This could be in relation with the position of sites. Indeed site $\mathrm{C} 5$ is closed to shellfish cultivation, whereas site $\mathrm{C} 4$ is in the central part of the basin. Therefore, the proximity of the shore and of oyster farming at site C5 may explain the higher variability and the marked seasonal signal of bioturbation and radionuclide fluxes.

The interest of ${ }^{234} \mathrm{Th}$ is to have a rather well constrained input due to its continuous and constant production from ${ }^{238} \mathrm{U}$ within the considered environment. It is then possible to compare fluxes at the water-sediment interface, calculated from ${ }^{234} \mathrm{Th}$ profiles in sediment, to its production rate in the overlying water column (Figure 3). For site C4, fluxes are always lower to production rate. On the opposite, at site $\mathrm{C} 5$, the highest fluxes measured in the sediment far exceed production rates. This process, resulting on preferential sites for removing of reactive elements from the water column, was observed on continental margin and called boundary scavenging [15]. For the Thau Lagoon, this observation seems to indicate that site C5 could act seasonally as a deposit center for particle-reactive elements.

\subsection{Significance of bioturbation rates}

One could address the question of the pertinence of the use of steady-state approximation to seasonal data series. It is the reason for which we attempt to estimate the bias induced by steady-state modeling of time-series data. To test the validity of the steady-state approximation, we calculate radionuclide profiles submitted to transient flux at the sediment-water interface. In that case, we solve equation (1) using a numerical scheme (see details in [16]). The evolution through time of radionuclide profile in response to flux variations is iteratively derived from equation (1). 
$\mathrm{D}_{\mathrm{b}-\mathrm{ss}}$ calculation from the modeled transient profiles strictly follows the same method than that adopted previously using the steady-state approximation. For each time step, the modeled transient profile is sampled every $0.5 \mathrm{~cm}$ from the sediment-water interface down to a $3.5 \mathrm{~cm}$. Therafter, we calculate the apparent bioturbation coefficient $\left(D_{b}-S S\right)$. Finally, we compare $D_{b-s s}$ to the actual $D_{b}$ initially introduced in the model.

The difference between the two $D_{b}$ constitutes a quantitative parameter to constrain the error introduced by the steady-state approximation and is related to the transient state imposed by the time-dependent flux at the sediment-water interface. By systematically varying the parameters of the model (the actual $D_{b}$ and the amplitude of flux variations at the SWI), we can estimate the sensitivity of the calculation to main environmental parameters.

By example, to test the effect of seasonal variations, we simulate a time-dependent flux at the sediment-water interface as:

$$
F=\mathrm{F}_{\mathrm{m}}+\mathrm{F}_{\mathrm{a}} \sin \left(\frac{2 \pi t}{\mathrm{~T}}\right)
$$

where $F_{m}$ is the mean flux, $F_{a}$ and $T$ are the amplitude and the period of the sinusoidal oscillations. In our analyses, $\mathrm{T}$ is always fixed to 1 year. This study showed that the relative error reaches significant values with the set of parameters classically encountered in coastal environments. The steady-state approximation is more sensible with ${ }^{7} \mathrm{Be}$ than with ${ }^{234} \mathrm{Th}$ due to the difference of half-life of their isotopes. The relative error can reach the extreme values of $163 \%$ with the first radioisotope and $74 \%$ with the second one. The error appears more sensitive to the amplitude of the flux oscillations than to the actual value of the bioturbation coefficient.

\section{CONCLUSION}

This investigation of short term sedimentation at the water-sediment interface of the Thau Lagoon allowed to establish an unique time-series of ${ }^{234} \mathrm{Th}$ and ${ }^{7} \mathrm{Be}$. Both radionuclides show seasonal variations in activities and in penetration within the sediment, indicating changes in mixing intensity and radionuclide fluxes. Results at site $\mathrm{C} 5$ indicate a greater variability in particle accumulation, likely in relation with its position nearby oyster farming and shore. The comparison of the production rate of ${ }^{234} \mathrm{Th}$ in the water column and ${ }^{234} \mathrm{Th}$ fluxes seems to indicate temporary boundary scavenging at site $\mathrm{C} 5$. Such a process, although seasonal, may have an effect on the accumulation of particle-reactive elements at this site.

This study finally shows that the steady state approximation, often used to derive bioturbation rates from radionuclide profiles, could introduce significant errors. Nevertheless, when duplicate cores are sampled, a scattering of bioturbation rates is noticeable, especially at low rates. Both observations highlight that radionuclides are a good, but of moderate precision, method to estimate bioturbation rate. Recommendations to improve the precision of this method are for coastal environment: - to collect replicate cores, - to increase slicing resolution, and - to measure flux at the sediment-water interface in order to constrain the impact of the transient-regime on the bioturbation coefficient calculation.

\section{Acknowledgments}

This work was supported by the PNEC-ART programme, the CNRS, the University of Bordeaux 1 and the CEA. We thank the IFREMER for logistic support. We are grateful to COM and LGE diving teams (R. Graille, B. de Ligondès, F. Zuberer; Didier Jézequel G. Sarazin) for their skilled work on the field. English corrections kindly provided by Th. Mulder improved this manuscript. This is EPOC-DGO $n^{\circ} \mathrm{xxxx}$ and LSCE $\mathrm{n}^{\circ} \mathrm{xxxx}$, contributions. 


\section{References}

[1] Labonne M., Othman D.B. and Luck J.-M., Chem. Geol. 181 (2001) 181-191.

[2] Gangnery A., Bacher C. and Buestel D., Can. J. Fish. Aquatic Sci. 58 (2001) 1012-1020.

[3] Le Monde, Edition du 05 Janvier 2004.

[4] Chapelle A., Menesguen A., Deslous-Paoli J.-M., Souchu P., Mazouni N.,Vaquer A. and Millet B., Ecol. Modelling 127 (2000) 161-181.

[5] Appleby P.G. and Olfield F., Uranium-series Disequilibrium: Applications to Earth, Marine, and Environmental Sciences (Clarendon Press, Oxford, 1992) pp. 731-778.

[6] Schmidt S., Jouanneau J.-M., Weber O., Lecroart P., Radakovitch O., Gilbert F. and Jezequel D., Estuar. Coast. Shelf Sci. (submitted).

[7] Schmidt S., van Weering T.E. de Stigter H.C., Marine Geology 173 (2001) 55-67.

[8] Aller R.C. and Cochran J.K., Earth Planet. Sci. Lett. 29 (1976) 37-50.

[9] Schmidt S., van Weering Tj.E., Reyss J.-L. and van Beek, P., Prog. Oceanogr. 52 (2002) 331-348.

[10] Olsen C.R., Larsen I.L., Lowry P.D., Cutshall N.H., Todd J.F., Wong G.T.F. and Casey W.H., J. Geophys. Res. 90 (1985) 10487-10495.

[11] Berner R.A., Early diagenesis, a theoretical approach (University Press, Princeton, 1980) p. 241.

[12] Boudreau B., Diagenetic models and their implementation: modelling, transport and reactions in aquatic sediments (Springer Verlag, Berlin, 1997) p. 414.

[13] Fuller C.C, van Geen A., Baskaran M. and Anima R., Mar. Chem. 64 (1999) 7-27.

[14] Olsen C.R, Larsen I.L., Lowry P.D., Cutshall N.H. and Nichols M.M., J. Geophys. Res. 91 (1986) 896-908.

[15] Bacon M.P., Phil. Trans. R. Soc. Lond. 325 (1988) 147-160

[16] Lecroart P; Schmidt S. and Jouanneau J.-M., Limnol. Oceanogr. (submitted). 